\title{
$N 62-12330$
}

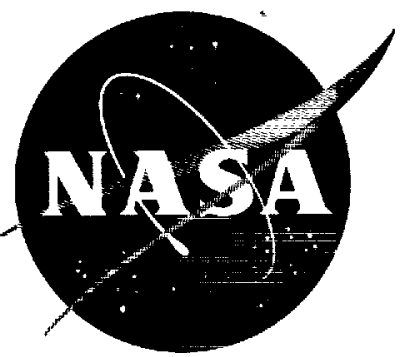

TECHNICAL NOTE

D-1339

\section{BEARINGS FOR VACUUM OPERATION RETAINER MATERIAL AND DESIGN}

Harold E. Evans and Thomas W. Flatley

Goddard Space Flight Center

Greenbelt, Maryland

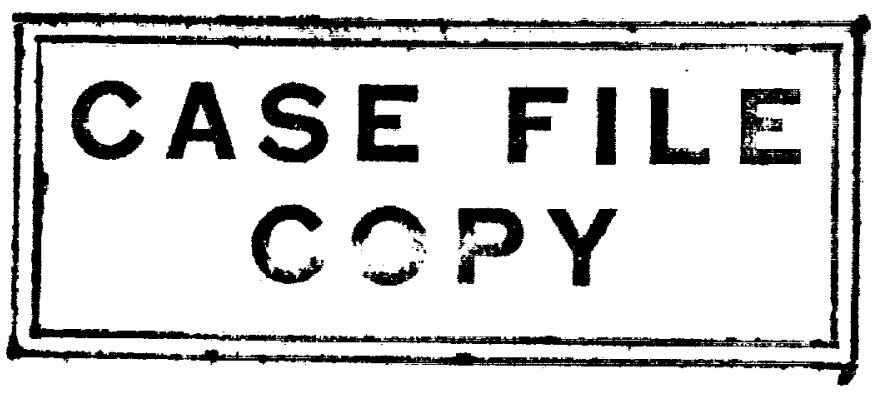

NATIONAL AERONAUTICS AND SPACE ADMINISTRATION WASHINGTON

May 1962 


\section{NOTICE}

THIS DOCUMENT HAS BEEN REPRODUCED FROM THE BEST COPY FURNISHED US BY THE SPONSORING AGENCY. ALTHOUGH IT IS RECOGNIZED THAT CERTAIN PORTIONS ARE ILLEGIBLE, IT IS BEING RELEASED IN THE INTEREST OF MAKING AVAILABLE AS MUCE INFORMATION AS POSSIBLE. 


\title{
BEARINGS FOR VACUUM OPERATION RETAINER MATERIAL AND DESIGN
}

\author{
by \\ Harold E. Evans and Thomas W. Flatley \\ Goddard Space Flight Center
}

\section{SUMMARY}

This report describes the initial phase of an investigation of the high speed operation of miniature ball bearings, with metallic film lubrication, in a vacuum environment.

Phase I of this study was conducted to determine the most promising retainer material and design for use in a general study of the effectiveness of various metallic coatings as lubricants. Fully machined retainers of five different materials, with all balls and races of gold plated $440 \mathrm{C}$ stainless steel, were tested. Both pure gold plating and gold with additives were investigated. Size R2-5 bearings were run without external loading at a nominal motor speed of $10,000 \mathrm{rpm}$ and the goal is a bearing life of 1,000 hours in an ambient pressure of $10^{-7}$ torr.

The results show that: (1) Thin metallic films as lubricants show real promise when used in a vacuum environment; (2) pure gold plating is not as effective as the plating with additives; (3) fully machined retainers provide good performance, and the use of relatively hard retainer materials significantly extends the useful life of the bearings; and (4) the bearing failures tended to be catastrophic rather than gradual, making the prediction of the onset of failure difficult.

A special multi-port oil-free vacuum system designed and built for this program proved extremely effective in achieving a vacuum of $10^{-7}$ torr, and in permitting the operation of seven individual tests at one time. 


\title{
BEARINGS FOR VACUUM OPERATION RETAINER MATERIAL AND DESIGN
}

\author{
by \\ Harold E. Evans and Thomas W. Flatley \\ Goddard Space Flight Center
}

SUMMARY

This report describes the initial phase of an investigation of the high speed operation of miniature ball bearings, with metallic film lubrication, in a vacuum environment.

Phase I of this study was conducted to determine the most promising retainer material and design for use in a general study of the effectiveness of various metallic coatings as lubricants. Fully machined retainers of five different materials, with all balls and races of gold plated $440 \mathrm{C}$ stainless steel, were tested. Both pure gold plating and gold with additives were investigated. Size R2-5 bearings were run without external loading at a nominal motor speed of $10,000 \mathrm{rpm}$ and the goal is a bearing life of 1,000 hours in an ambient pressure of $10^{-7}$ torr.

The results show that: (1) Thin metallic films as lubricants show real promise when used in a vacuum environment; (2) pure gold plating is not as effective as the plating with additives; (3) fully machined retainers provide good performance, and the use of relatively hard retainer materials significantly extends the useful life of the bearings; and (4) the bearing failures tended to be catastrophic rather than gradual, making the prediction of the onset of failure difficult.

A special multi-port oil-free vacuum system designed and built for this program proved extremely effective in achieving a vacuum of $10^{-7}$ torr, and in permitting the operation of seven individual tests at one time. 
CONTENTS

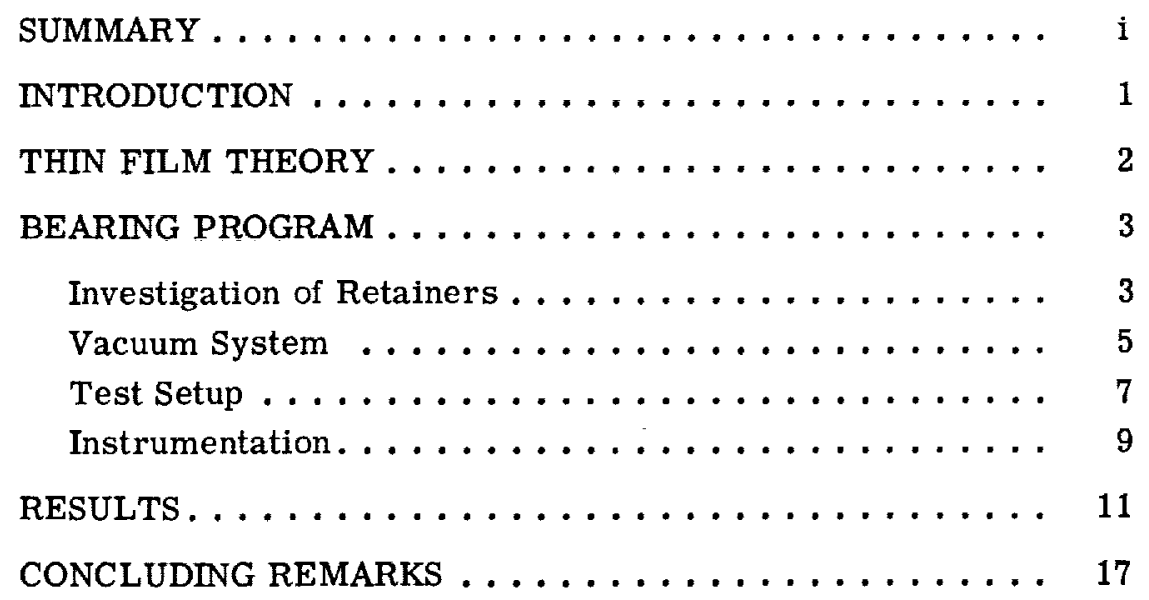




\title{
BEARINGS FOR VACUUM OPERATION RETAINER MATERIAL AND DESIGN
}

\author{
by \\ Harold E. Evans and Thomas W. Flatley \\ Goddard Space Flight Center
}

\section{INTRODUCTION}

The environment of outer space presents four basic problems with regard to systems and components where relative motion must be maintained for extended periods:

1. Extremely low ambient pressure (vacuum);

2. Radiation;

3. Presence of meteoroids; and

4. Absence of gravitational effects.

Of these, the problem of low pressure is the most difficult to solve from the standpoint of friction and wear. Hermetic sealing of devices is not always possible or even desirable; hence some units must operate when exposed directly to the space environment. Examples of such devices are horizon seekers, star finders, radar antennas, solar paddles, and telescope pointing mechanisms.

Normal liquid and semi-solid grease lubricants have vapor pressures higher than the ambient pressures in outer space (estimated at $10^{-13}$ torr interplanetary and $10^{-16}$ torr interstellar) ${ }^{*}$; hence these lubricants evaporate rapidly. The absence of oxygen in space creates additional problems. Normally, oxide layers form on metallic surfaces and act as thin film lubricants; these layers are subject to rupturing, but reform quickly in the presence of oxygen. In space, where oxidation cannot occur, the protective oxide layer cannot be repaired once it is broken.

Radiation poses more of a problem in the materials and life sciences field than in friction and wear studies. Some lubricants undergo a phase change when irradiated, but this can probably be overcome more readily than the vacuum problem. For example, the

"Bisson, E. E., "Friction and Bearing Problems in the Vacuum and Radiation Environments of Space." Lecture presented at Course on Bearing Technology held at the University of California, Los Angeles, November $1961, p .2$ 
approach taken in this investigation (thin metallic film lubrication) solves the radiation problem because metallic films are radiation-resistant.

The presence of meteoroids becomes important where hermetically sealed systems are used: meteoroid impacts could destroy a hermetic seal.

The zero $g$ effect is not expected to be of major importance in the thin film study, but it could be a significant factor if a wet lubricant is to be contained in a system. In many applications the zero $g$ effect could be very beneficial, since it will greatly reduce the normal forces acting on the surfaces in contact.

Possible solutions to the friction and wear problems in a vacuum environment fall into five basic categories, involving the use of low vapor pressure oils and greases; laminar solids ( $\mathrm{MoS}_{2}, \mathrm{PbO}$, etc.); metallic films; plastics; and ceramics (materials of extremely high elastic modulus).

In this study, the metallic film approach is taken.

\section{THIN FILM THEORY}

It is well known that thin films such as oxide coatings have a marked effect on friction and wear between surfaces. It is also known that a certain degree of roughness exits even on a highly polished surface. Magnified many times, such a "polished" surface resembles a mountain range. When two surfaces move relative to each other, areas of extreme stress exist where these "mountains" come into contact. The stress levels reached at these interfaces are high enough to cause crushing of the "mountain tops".

Bowden and Tabor" and Merchant"* advanced the adhesion theory of friction. This theory holds that crushing of the "mountain tops" creates small areas of plastic flow which result in small cold welds. Relative motion between parts then requires that shearing take place in the weld or in the base metal proper. The theory also states that a friction force is made up of a shear term and a ploughing term. The shear term represents the force required to break the welded junctions, and the ploughing term represents the force required to displace "mountain tops" of a softer material by a harder material. Experience has shown that the ploughing term is, in general, quite small and the shear term is the governing friction factor. Hence, friction is usually expressed only by the shear term:

$$
\mu=\frac{\mathbf{S}}{\mathbf{P}}
$$

where $\mu$ is the coefficient of friction, $\mathbf{S}$ the shear strength of welded junctions, and $\mathrm{P}$ the flow pressure.

"Bowden, F. P. and Tabor, D., "The Friction and Lubrication of Solids," Orford: Clarendon Press, 1950

"*Merchant, M. E., "The Mechanism of Static Friction," J. Appl. Phys. 11(3):230, March 1940 
Obviously $\mu$ can be reduced if the shear strength is decreased or the flow pressure is increased. It is unlikely that both of these properties will be found in one material. However, Bowden and Tabor demonstrated that the use of lead and indium, applied as low shear strength films on hard base materials, achieves both desirable effects. This soft film effect forms the basis for the program reported here.

\section{BEARING PROGRAM}

The investigation of thin soft metallic films as a means of lubricating ball bearings in a vacuum environment is being conducted in conjunction with New Hampshire Ball Bearings, Inc., of Peterborough, New Hampshire. The objective is a ball bearing design that will operate successfully for a minimum of 1,000 hours at $10,000 \mathrm{rpm}$ in a vacuum of $10^{-7}$ torr.

Some background information was available on gold plated bearings, since these were used in the electric field meter flown on Explorer VIII (1960 $\xi$ ). It was therefore decided that this bearing would be the initial "standard" test vehicle.

\section{Investigation of Retainers}

Since the major cause of bearing failure in the development of the electric field meter* was the retainer, the first phase of the study would consist of establishing the most promising retainer by using the "standard" gold-plated bearing. Phase II would then be conducted by using this new retainer and varying the types of plating.

The basic Phase I program involved fully machined retainers of five different material combinations, and employed two separate sources of gold plating. Plate $\mathrm{A}^{* *}$ was 23.88 carat gold with additives (nickel, indium and cobalt) to improve its adherence, hardness, and brightness; and plate B was almost 24 carat (or pure) gold. A typical set of bearing components is shown in Figure 1. Bearings with crown-type retainers, standard except that all the components were gold-plated, were also run to provide a comparison of retainer configurations.

The bearings were run in pairs and, in all, fifty bearings were tested. A summary of the various combinations is given in Table 1 .

*Flatley, Thomas W. and Evans, Harold E., "The Development of the Electric Field Meter for the Explorer VIII Satellite (1960))," NASA Technical Note D-1044, 1962

**Acid gold depositing solution supplied by Lea-Ronal Mfg. Co., Jamaica, New York 


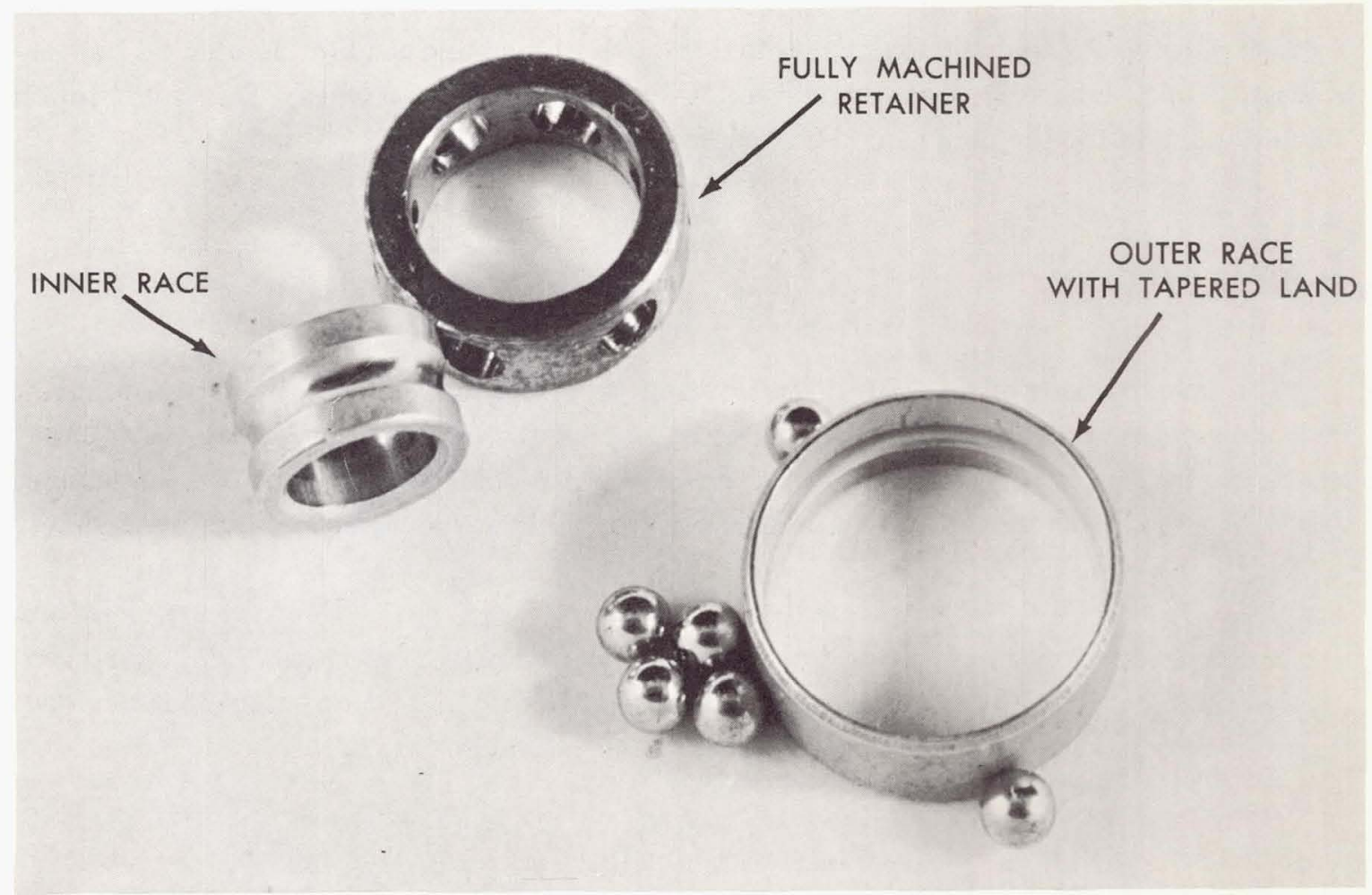

Figure 1 - Typical set of bearing components

Table 1

Bearings employed in Phase I of the study

\begin{tabular}{|l|c|c|c|}
\hline \multirow{2}{*}{ Retainer Type and Material } & \multicolumn{2}{|c|}{ Gold-plating Source } & \multirow{2}{*}{$\begin{array}{c}\text { Number of } \\
\text { Bearings }\end{array}$} \\
\cline { 2 - 3 } & Balls & Races & 4 \\
Machined, gold-plated silnic bronze & A & A & 4 \\
Machined, gold-plated silnic bronze & B & B & 4 \\
Machined, 2.5\% beryllium copper & A & A & \multicolumn{2}{|c|}{4} \\
Machined, 2.5\% beryllium copper & B & B & 4 \\
Machined, 2.5\% beryllium copper & B & A & \multicolumn{2}{|c|}{4} \\
Machined, silnic bronze & A & A & 2 \\
Machined, silnic bronze & B & B & \multicolumn{2}{|c}{4} \\
Machined, S-Inconel & A & A & 4 \\
Machined, S-Inconel & B & B & 4 \\
Machined, silver-plated circle C & A & A & 2 \\
Machined, silver-plated circle C & B & B & 4 \\
Machined, silver-plated circle C & B & A & 6 \\
Crown, 410 Stainless Steel & A & A \\
\hline
\end{tabular}




\section{Vacuum System}

Because the bearings were to operate without the benefit of oil film lubrication, a vacuum system completely free of oil diffusion pumps was required, since experience has shown that it is extremely difficult to isolate all pump oil from vacuum chambers, even when extensive cold trapping and baffling are employed. To meet this requirement a special pumping system, employing ion-getter type high-vacuum pumping and a cryogenic roughing pump, was designed and built.

Since the test program called for a large number of bearing tests, a versatile system was required - one that would permit testing of many bearings at one time, and also allow access to each unit under test without disturbing the other tests. The system designed for use in the bearing test program is known as the Heptavac.

Figure 2 shows the layout of the system. Basically, it consists of a 90 -in. ${ }^{3}$ main chamber surrounded by seven $10-$ in. $^{3}$ individual test chambers. The main chamber is connected directly to a 40 liter/second ion pump. Figure 3 shows a close-up of a typical test chamber, which is connected to the main chamber by a 1-inch all-metal valve, and has its own 8 liter/second ion pump. In addition, a small 1/4-inch all-metal valve is included to vent the chamber to the atmosphere or to connect to the roughing pump as required. The chamber cap, like all other joints in the system, is sealed with a copper shear gasket. Electrical connections are made through a hermetically sealed connector which is silver-soldered in the cover cap.

The entire system is portable and, with pump magnets removed, may be baked to $550^{\circ} \mathrm{C}$. The chief function of the main chamber is secondary roughing to accelerate the starting of the small pumps, but it is also available for use as a test chamber if required. The cryogenic roughing pump achieves pumping action through the sorption of gas by a molecular sieve chilled externally by liquid nitrogen.

Chamber pressures are determined with gauges integral with the pump power supplies, operating on the principle that the pump current is a function of ambient pressure. Pressures in the high $10^{-9}$ torr region are obtainable in the empty chambers, but the presence of the motor coils, owing to their outgassing, limits test pressures to about $10^{-7}$ torr. 


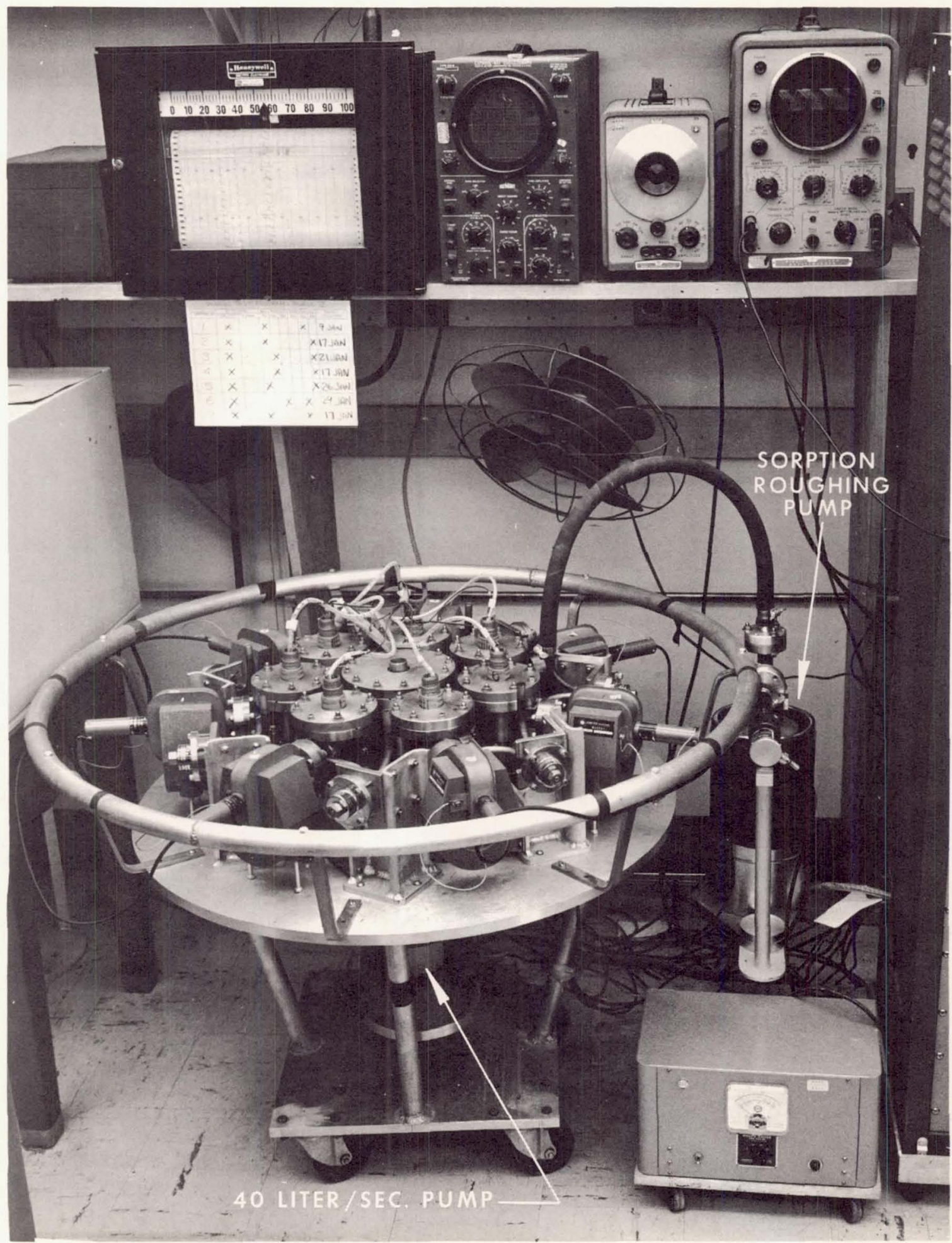

$\forall$
1
$\omega$
$\omega$
$\omega$ 


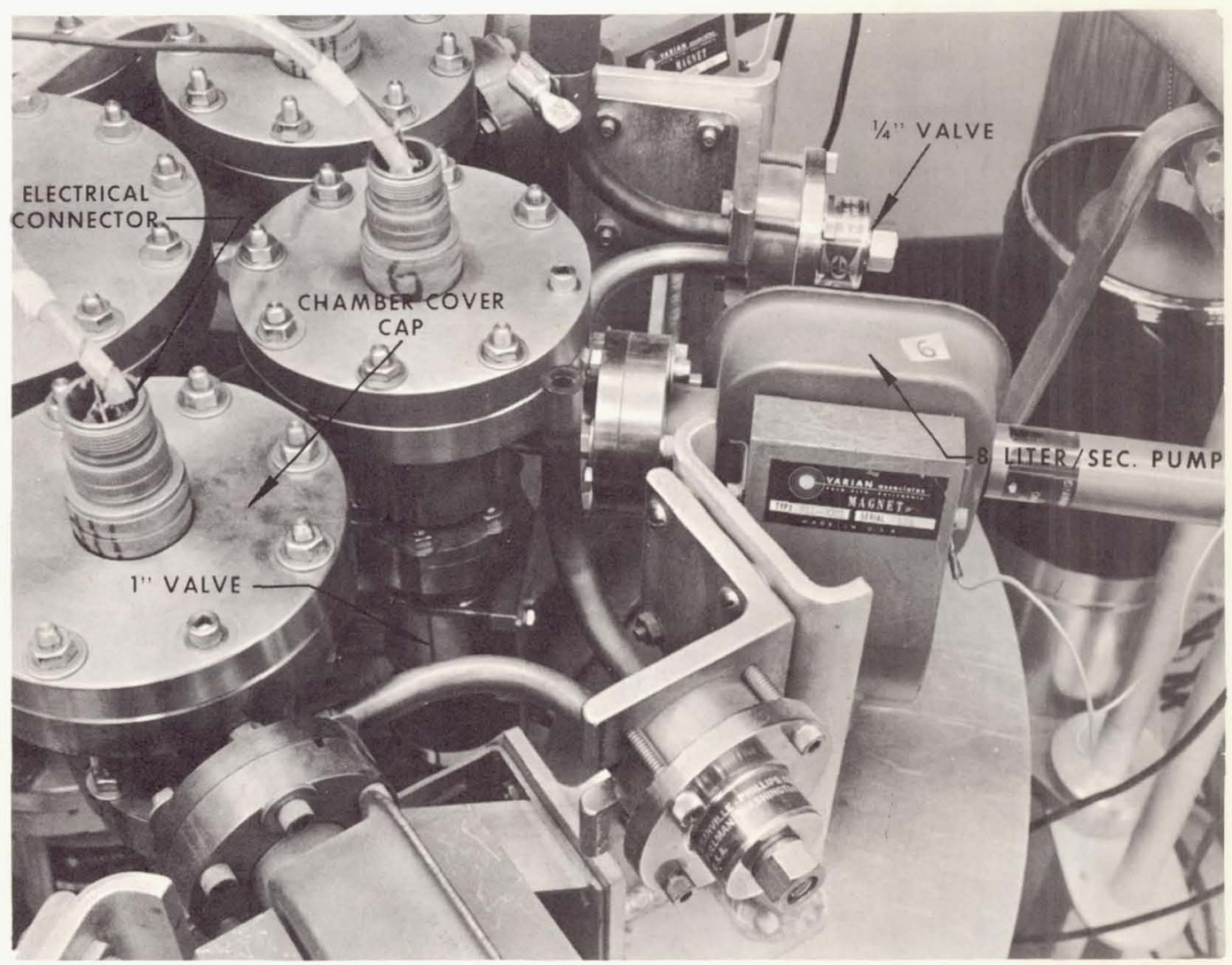

Figure 3 - Typical Heptavac test chamber

\section{Test Setup}

The basic element in the bearing test setup is a standard size-10 two-phase 400 -cps induction motor. The torque-speed characteristics of this type of motor make it ideal for evaluating bearing performance. The standard bearings in the motor are replaced by the bearings to be tested and a small iron 6-lobe wheel is attached to the motor shaft. Figure 4 shows the various components of the motor used as well as an assembled motor. Next to each bearing is a stainless steel bushing which adapts the R2-5 size bearings to the motor housing.

The assembled motor is mounted in a fixture permanently mounted to the test chamber cover cap (Figure 5). Thus mounted, the iron wheel completes a magnetic circuit which also includes a signal coil wrapped on a permanent magnet and magnetic stainless steel supports. This circuit generates an alternating voltage when the wheel turns, and the frequency of the signal generated gives an accurate indication of motor speed.

The motor operates on 26 volts and its no-load speed is approximately 11,000 rpm. The stall torque is $0.26 \mathrm{in.-oz}$. The motor speed varies linearly with the load. The motor power and the generator signal pass through a hermetically sealed connector which is silver-soldered to the chamber cover cap. Also passing through this connector is 


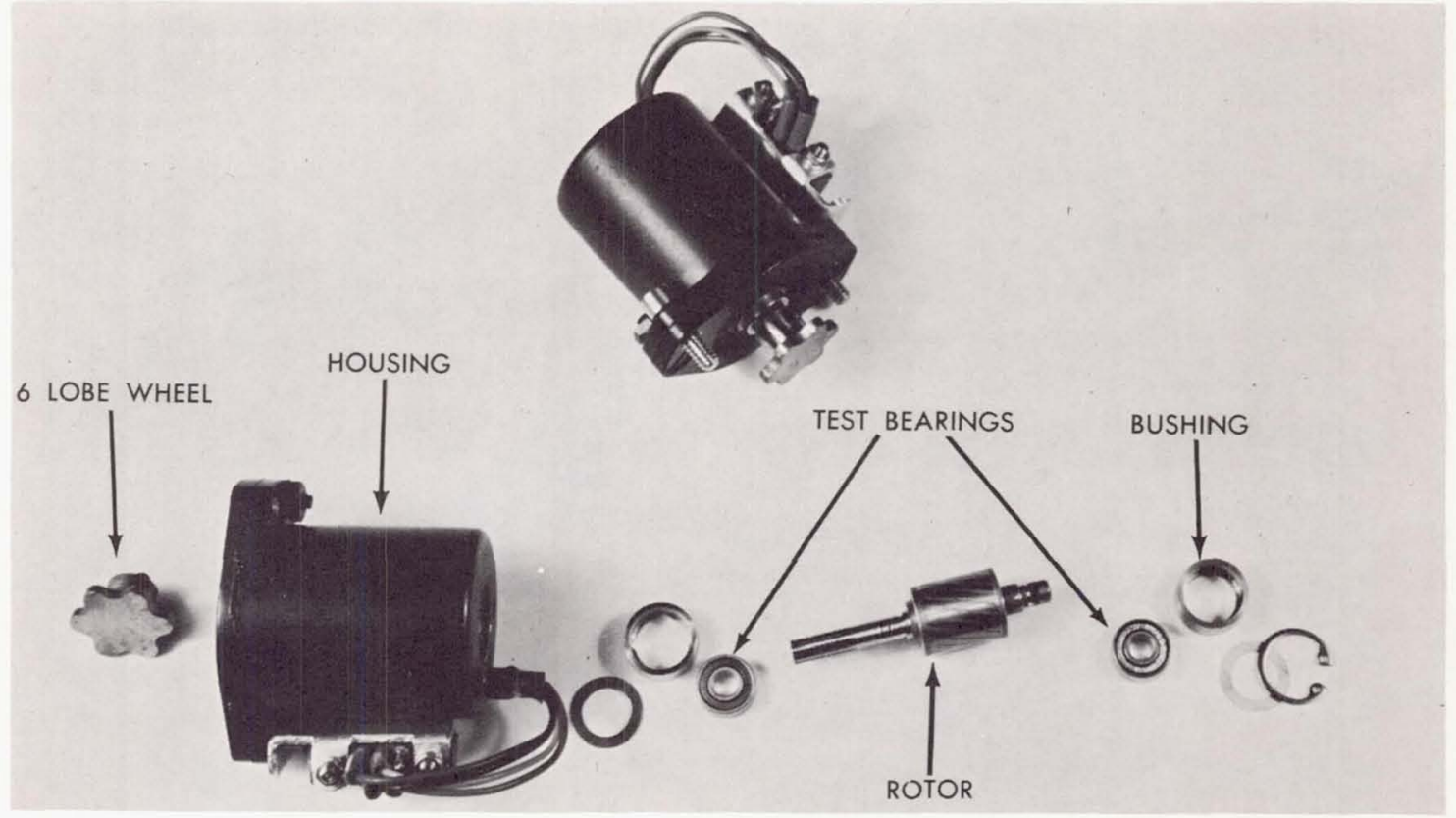

Figure 4 - Assembled and disassembled induction motor for the test setup

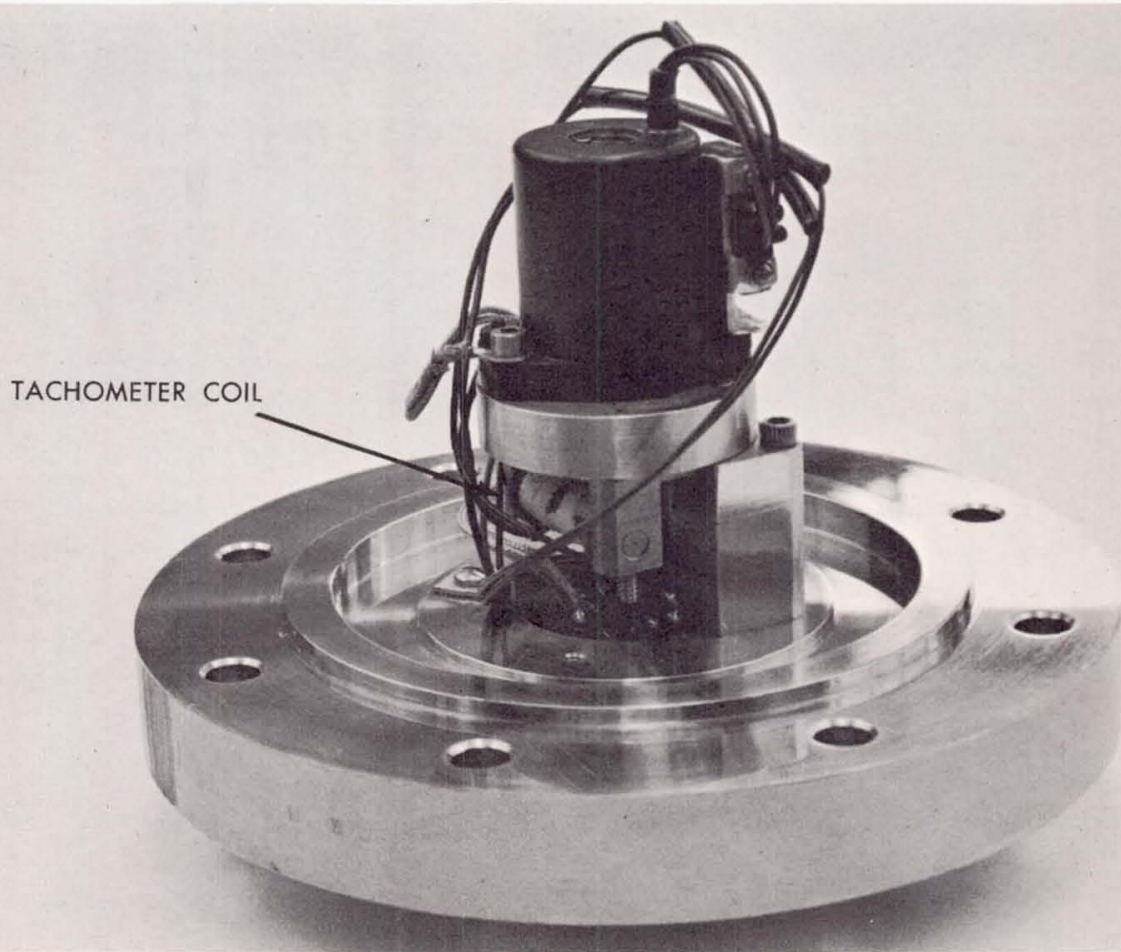

Figure 5 - Motor Assembly mounted on cover 
the signal from a thermocouple connected to the motor housing. This signal is fed into a multi-channel temperature recorder for temperature monitoring when required.

Test units are assembled and disassembled in a dust-free cabinet to insure cleanliness.

\section{Instrumentation}

The small signal generator in each bearing test unit was designed to produce an alternating voltage at a frequency six times greater than the motor speed as the motor shaft turns. This was done so that the number of cycles generated during a 10 -second interval would be numerically equal to the speed of the motor in rpm.

When the system is operating at full capacity, seven such signals are fed into a series of manual switches. These switches permit any one signal to be directed to any of seven inputs of an automatic sampling timer (Figure 6). A signal from the motor power supply is fed into the eighth input to the timer.

Operating on a 30-minute cycle, the timer samples each of the 8 input signals once per cycle for about 3-1/2 minutes. The signal being sampled is amplified and fed into an electronic counter with a 10 -second gate time. The outputs from the counter and from a digital clock are fed into a digital recorder which prints out the test data in the form of a time and a motor speed once every 20 seconds. The record also includes a check on the power supply frequency, since that frequency will affect the motor speed. Figure 7 shows the basic instrumentation racks, which also include the ion pump power supplies for the vacuum system. To provide a check on motor speed fluctuations, the amplified input signal is sometimes fed into the $\mathrm{X}$ input of an oscilloscope. The output of an oscillator is fed into the Y input, and speed consistency can be monitored by observing the Lissajous figures. This setup can also be used to determine the coast time when the motor power is cut off.

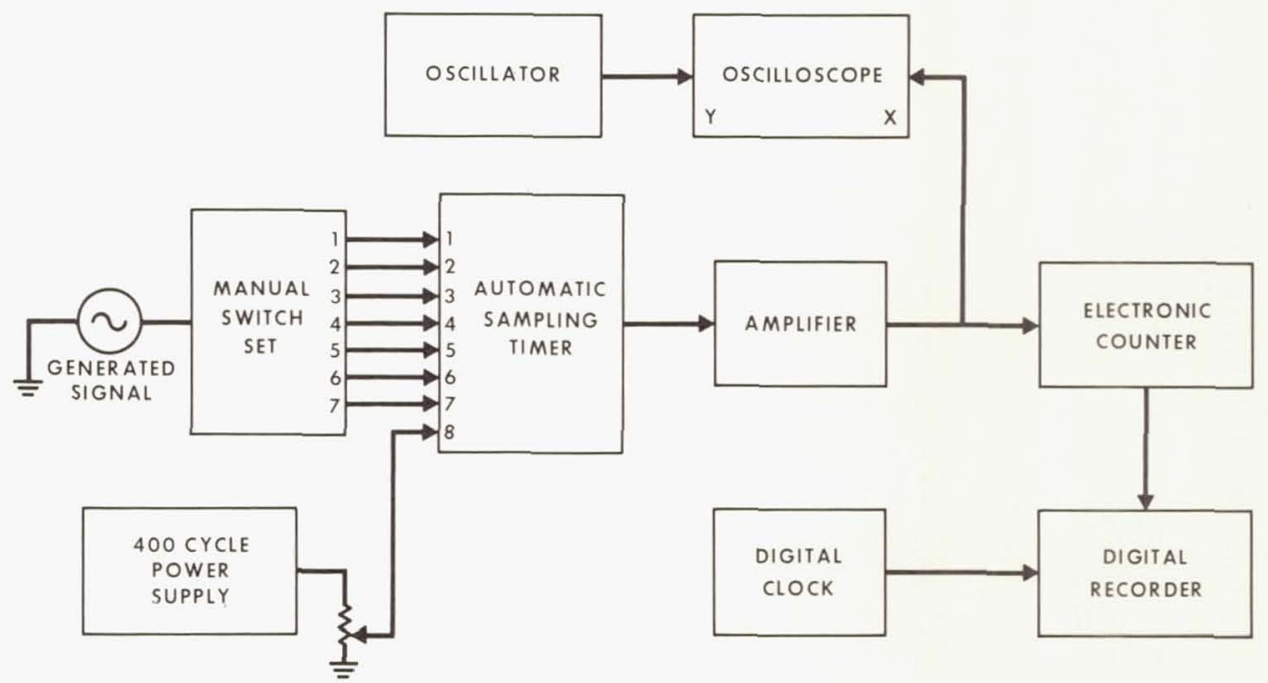

Figure 6 - Block Diagram of the instrumentation 


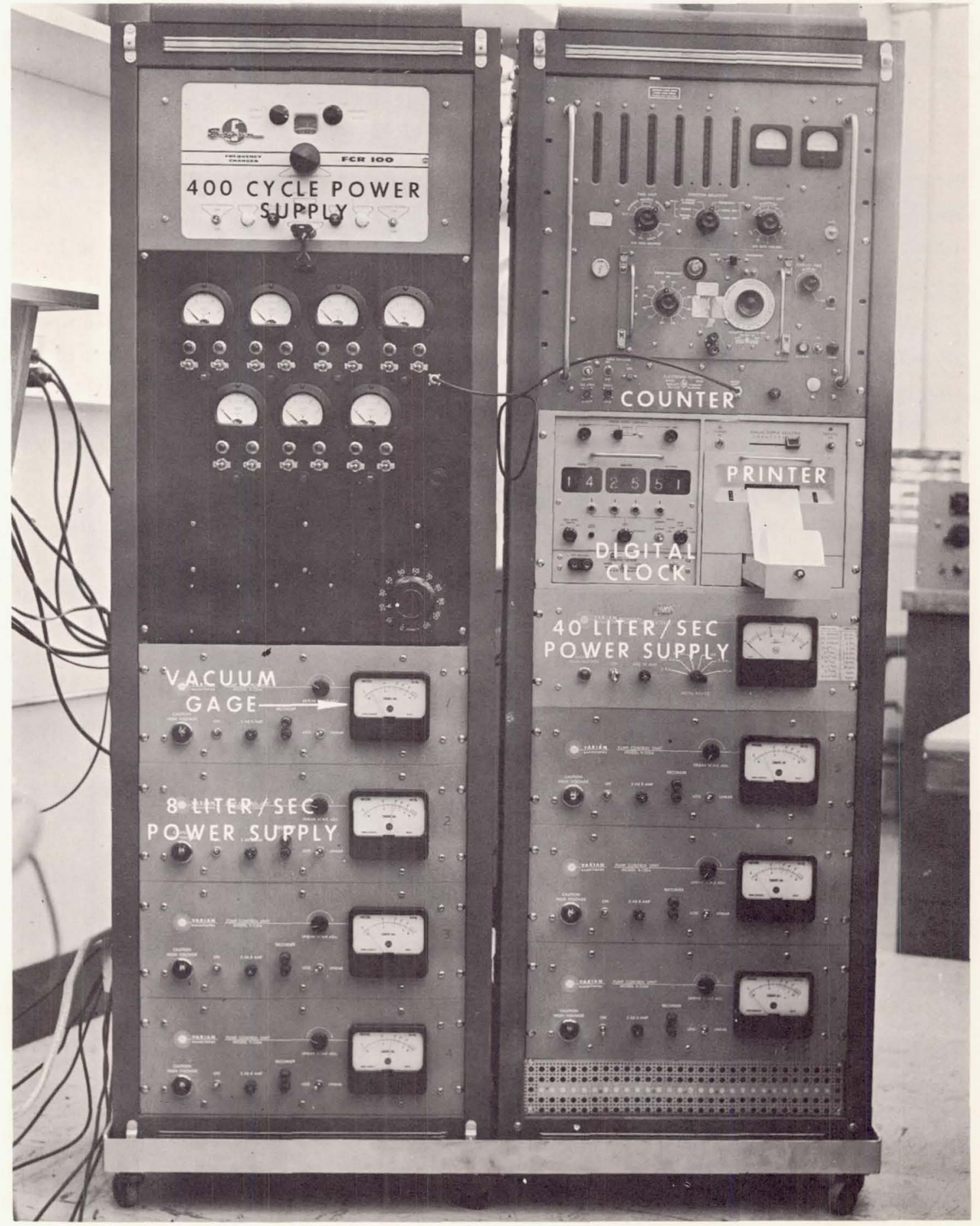




\section{RESULTS}

The results of the Phase I testing are presented in both tabular and graphical form in Figure 8 and Table 2. The graphical plot in particular demonstrates the predominant features of the test results: The better performance of the bearings with relatively hard retainer materials, and the relative superiority of gold plating A over $\mathrm{B}$.

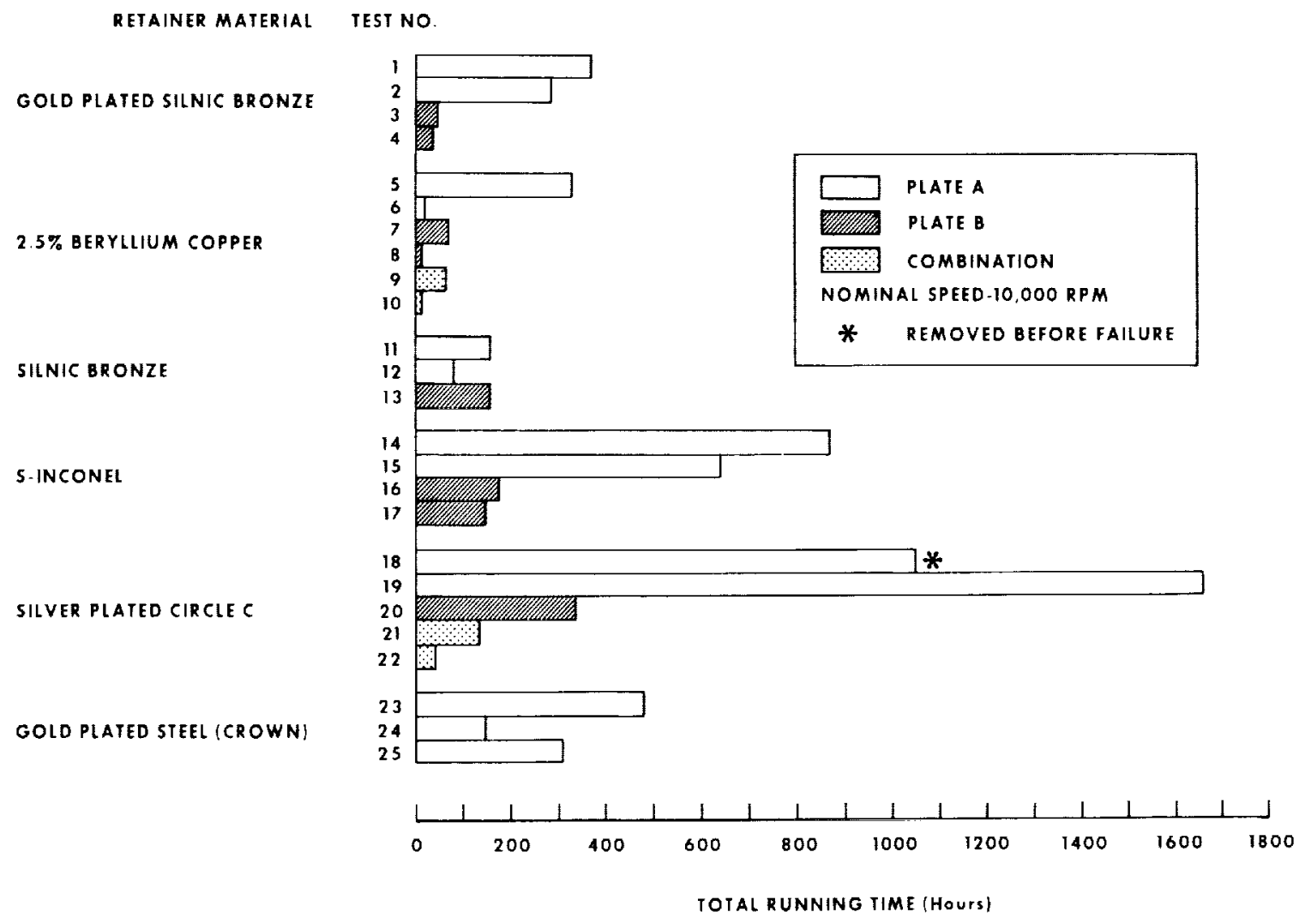

Figure 8 - Bearing performance data

The bearing failure in tests 1 through 13, with the softer retainers, was always caused by a loss of radial play, leading to internal interference. This condition was directly traceable to an accumulation of debris inside the bearing - a brown or black contamination which built up either evenly or ir regularly on the balls and raceways. A chemical analysis showed the contamination to be nearly all copper oxide but undoubtedly some gold was blended in with it. Another possible source of contaminant is the presence of the motor coil in the chamber and the outgassing associated with it. The contamination probably darkened in color because of oxidation of the wear particles from the copper alloy retainers when the bearings were exposed to the atmosphere after failure. 
Table 2

Test Results from Phase I of the study

\begin{tabular}{|c|c|c|c|c|}
\hline \multirow{2}{*}{$\begin{array}{c}\text { Retainer } \\
\text { Type and Material }\end{array}$} & \multicolumn{2}{|c|}{ Plate Source } & \multirow{2}{*}{ Test } & \multirow{2}{*}{$\begin{array}{c}\text { Lifetime } \\
\text { (Hours) }\end{array}$} \\
\hline & Balls & Races & & \\
\hline \multirow{4}{*}{ Machined, gold-plated silnic bronze } & \multirow[b]{2}{*}{ A } & \multirow[b]{2}{*}{ A } & 1 & 369 \\
\hline & & & 2 & 279 \\
\hline & \multirow[b]{2}{*}{$\mathrm{B}$} & \multirow[b]{2}{*}{ B } & 3 & 39 \\
\hline & & & 4 & 32 \\
\hline \multirow{6}{*}{ Machined, $2.5 \%$ beryllium copper } & \multirow{2}{*}{ A } & \multirow{2}{*}{ A } & 5 & 329 \\
\hline & & & 6 & 12 \\
\hline & \multirow[b]{2}{*}{ B } & \multirow[b]{2}{*}{ B } & 7 & 71 \\
\hline & & & 8 & 4 \\
\hline & \multirow{2}{*}{ B } & \multirow{2}{*}{ A } & 9 & 68 \\
\hline & & & 10 & 6 \\
\hline \multirow{3}{*}{ Machined, silnic bronze } & \multirow{2}{*}{ A } & \multirow[b]{2}{*}{ A } & 11 & 159 \\
\hline & & & 12 & 80 \\
\hline & $\mathrm{B}$ & B & 13 & 156 \\
\hline \multirow{4}{*}{ Machined, S-Inconel } & \multirow[b]{2}{*}{ A } & \multirow{2}{*}{ A } & 14 & 873 \\
\hline & & & 15 & 639 \\
\hline & \multirow[b]{2}{*}{ B } & \multirow[b]{2}{*}{ B } & 16 & 178 \\
\hline & & & 17 & 147 \\
\hline \multirow{5}{*}{ Machined, silver-plated circle C } & \multirow{2}{*}{ A } & \multirow{2}{*}{ A } & 18 & $1049^{*}$ \\
\hline & & & 19 & 1660 \\
\hline & B & B & 20 & 332 \\
\hline & \multirow{2}{*}{ B } & \multirow{2}{*}{ A } & 21 & 136 \\
\hline & & & 22 & 33 \\
\hline \multirow{3}{*}{ Crown, hardened 410 stainless } & \multirow{3}{*}{$\mathbf{A}$} & \multirow{3}{*}{ A } & 23 & 477 \\
\hline & & & 24 & 142 \\
\hline & & & 25 & 312 \\
\hline
\end{tabular}

* Removed before failure

The individual bearing "autopsies" showed that the adherence of gold plate A was greatly superior to that of plate B. The latter tended to flake off the contacting surfaces of the balls and races, considerably increasing the retainer wear and the accumulation of debris, and thus shortening the useful life of the bearing. In some cases with plate $B$, the build-up in the races and on the balls seemed to be almost all gold. Where combined platings were tested (tests 9 and 10), the plating on the races (A) adhered much better than that on the balls (B) and the overall performance of the combination seemed similar to the usual performance of $B$ alone. 
Severe ball pocket wear was evident in all the "soft" retainer testing, and adhesive wear had begun on the balls and races in places where the gold was lost. Of the 13 tests run, only five pairs of bearings lasted more than 100 hours and the maximum life obtained was 369 hours.

Greater success was obtained with harder retainer materials. In these tests (14 through 25), the type of failure experienced was different from those previously discussed in that the adhesive wear on the balls and races was a predominant factor.

The durability of gold plating A was demonstrated more vividly during these tests. Much of the plating remained intact even during the longest run (1660 hours).

Although internal interference again caused most of the failures, retainer wear contributed much less to the accumulation of debris than in the previous tests. Particles from the balls and races, loosened by adhesive wear, spalling, and galling, contributed significantly to the debris, much of which was in the form of a loose gray powder.

The gold plating, especially plate $\mathrm{A}$, delayed the start of the severe wear, thereby lengthening the operating life of the bearing. The silver plating on the Circle $\mathrm{C}$ probably contributed significant surface protection.

The performance of the crown retainer bearings shows the advantage of using a fully machined retainer in this program. The type of failure was similar to that discussed above, but the sharp edges of the retainer "ears" tended to cut the gold from the balls, limiting the life of the bearings.

Figures 9 through 14 are typical performance curves for the bearings tested in Phase I. The predominant features of these curves are:

1. An early dip in speed, or initial erratic performance; and

2. A sudden failure rather than a gradual decrease of speed.

The first point indicates that the bearings require a "run-in" period, perhaps to compress and improve the gold plated surface. The second characteristic shows that the running torque on the bearings is subject to catastrophic increase, making it impossible to predict the onset of failure.

During Phase I testing, some effort was directed toward further improving the performance of the Circle $C$ retainers. After preliminary testing, two items seem worthy of further investigation: the value of the silver plating, and the effect of hardening the Circle C. These variables will be further investigated in conjunction with early Phase II testing. Tentative plans for Phase $I$ of the study are outlined in Table 3. 
Table 3

Tentative configurations to be tested in Phase $\Pi$ of the study

\begin{tabular}{|c|c|c|}
\hline Retainer & Ball Plating & Race Plating \\
\hline \multirow{9}{*}{ Silver-plated circle C } & \multirow{3}{*}{ Barium } & Barium \\
\hline & & Silver \\
\hline & & Gold \\
\hline & \multirow{3}{*}{ Silver } & Barium \\
\hline & & Silver \\
\hline & & Gold \\
\hline & \multirow{3}{*}{ Gold } & Barium \\
\hline & & Silver \\
\hline & & Gold \\
\hline \multirow{9}{*}{ S-Inconel } & \multirow{3}{*}{ Barium } & Barium \\
\hline & & Silver \\
\hline & & Gold \\
\hline & \multirow{3}{*}{ Silver } & Barium \\
\hline & & Silver \\
\hline & & Gold \\
\hline & \multirow{3}{*}{ Gold } & Barium \\
\hline & & Silver \\
\hline & & Gold \\
\hline
\end{tabular}

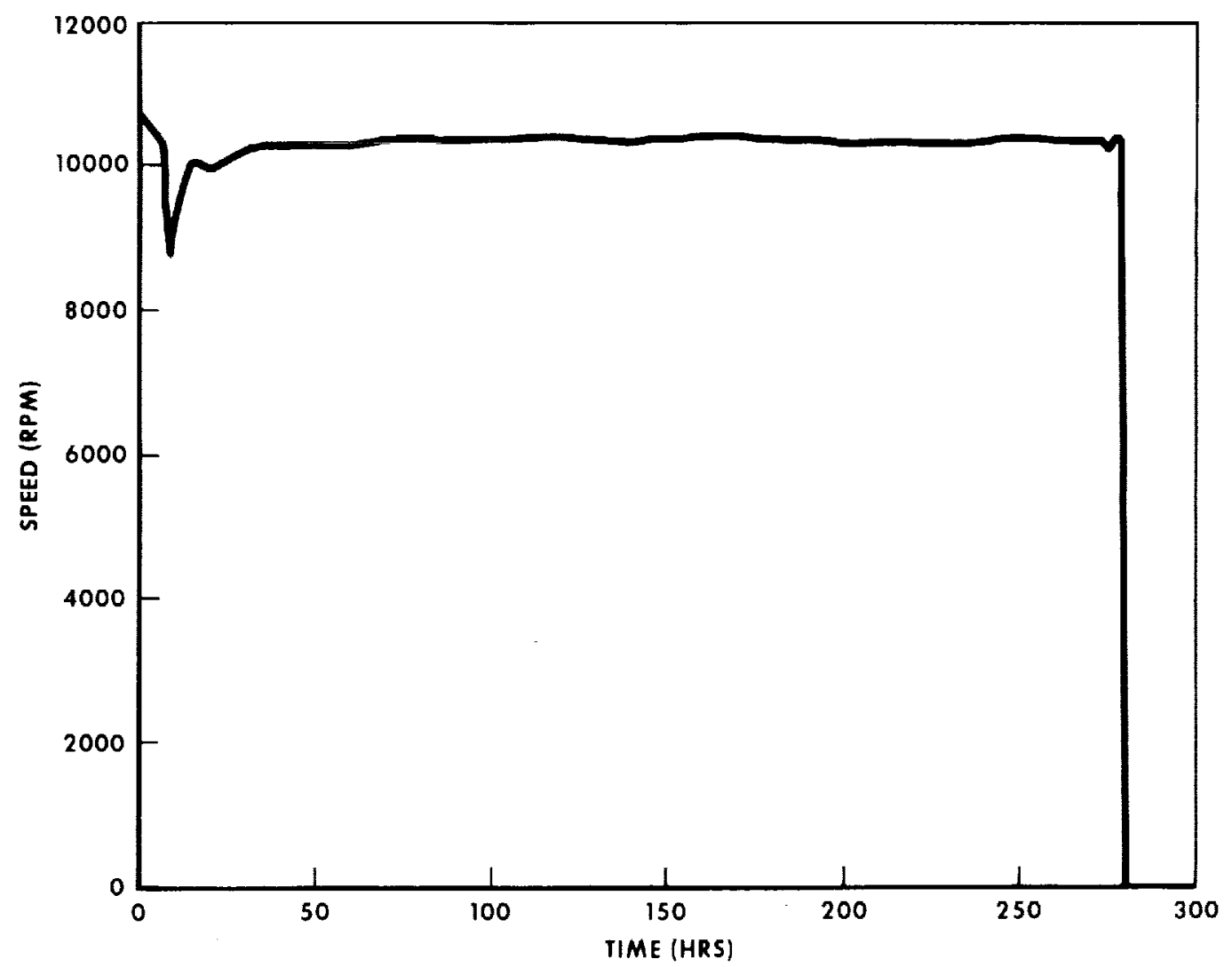




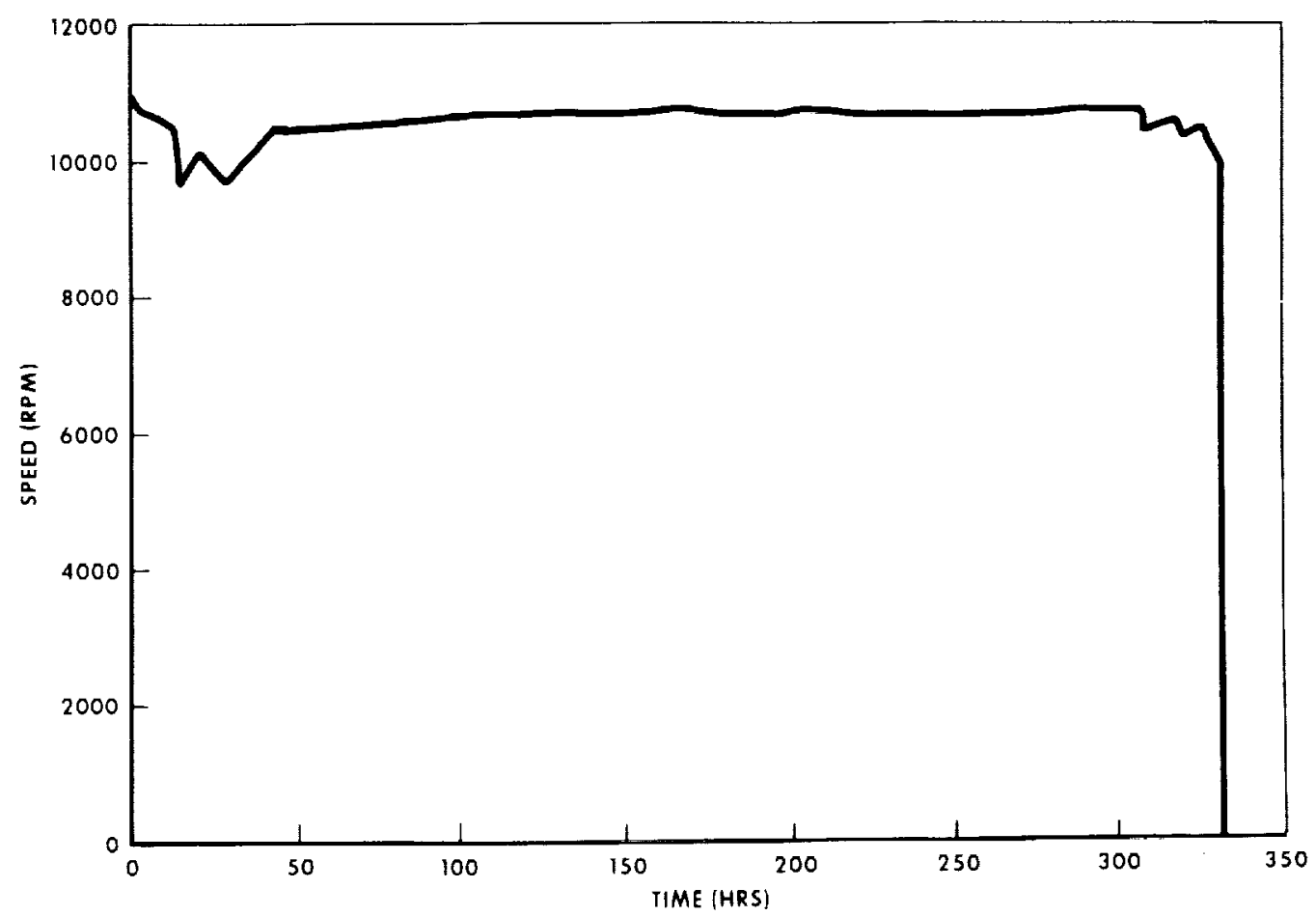

Figure 10 - Bearing test 5: R2-5 bearings, gold plated balls and races, and $2.5 \%$ BeCu retainer

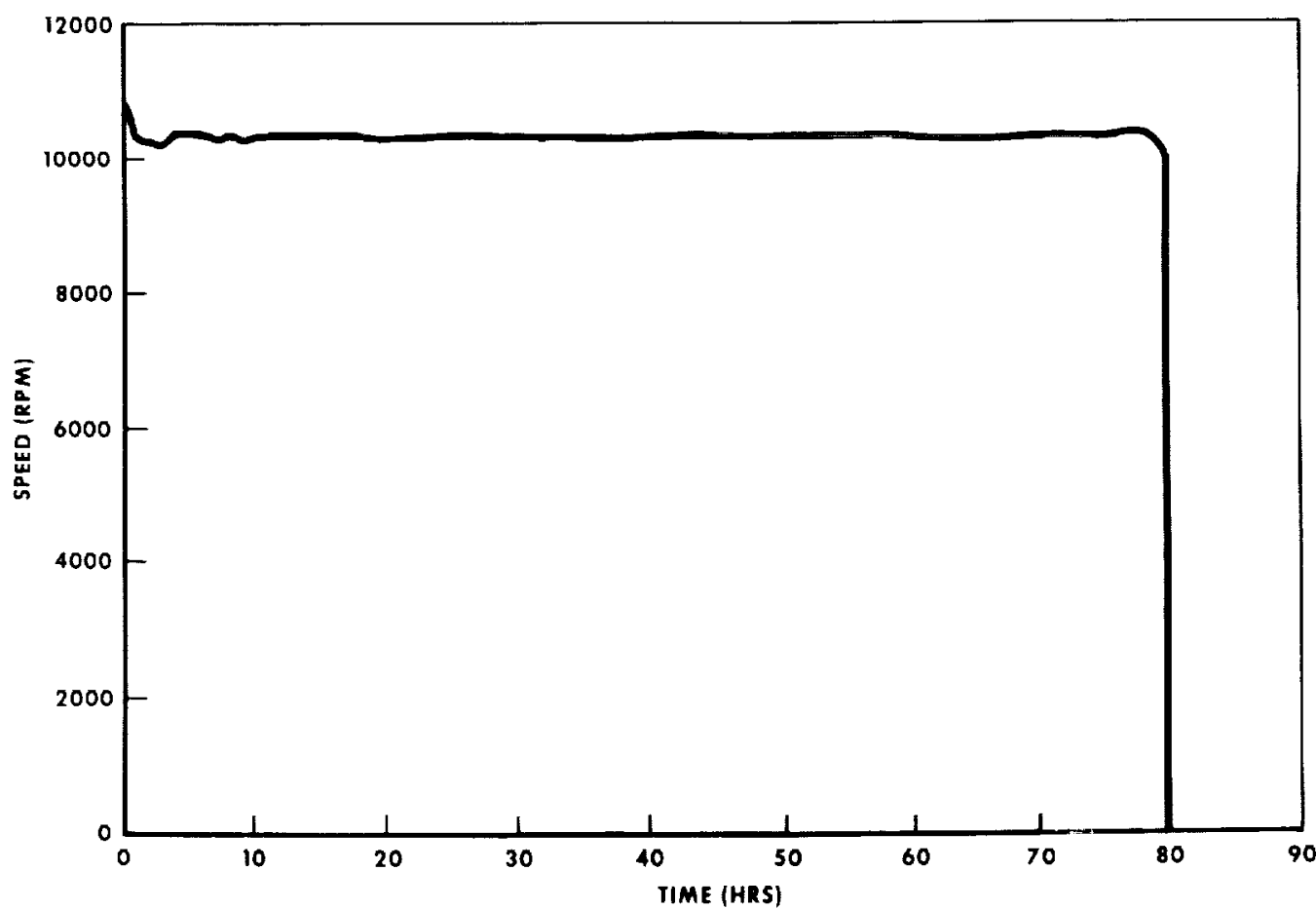

Figure 11 - Bearing test 12: R2-5 bearings, gold plated balls and races, and silnic bronze retainer 


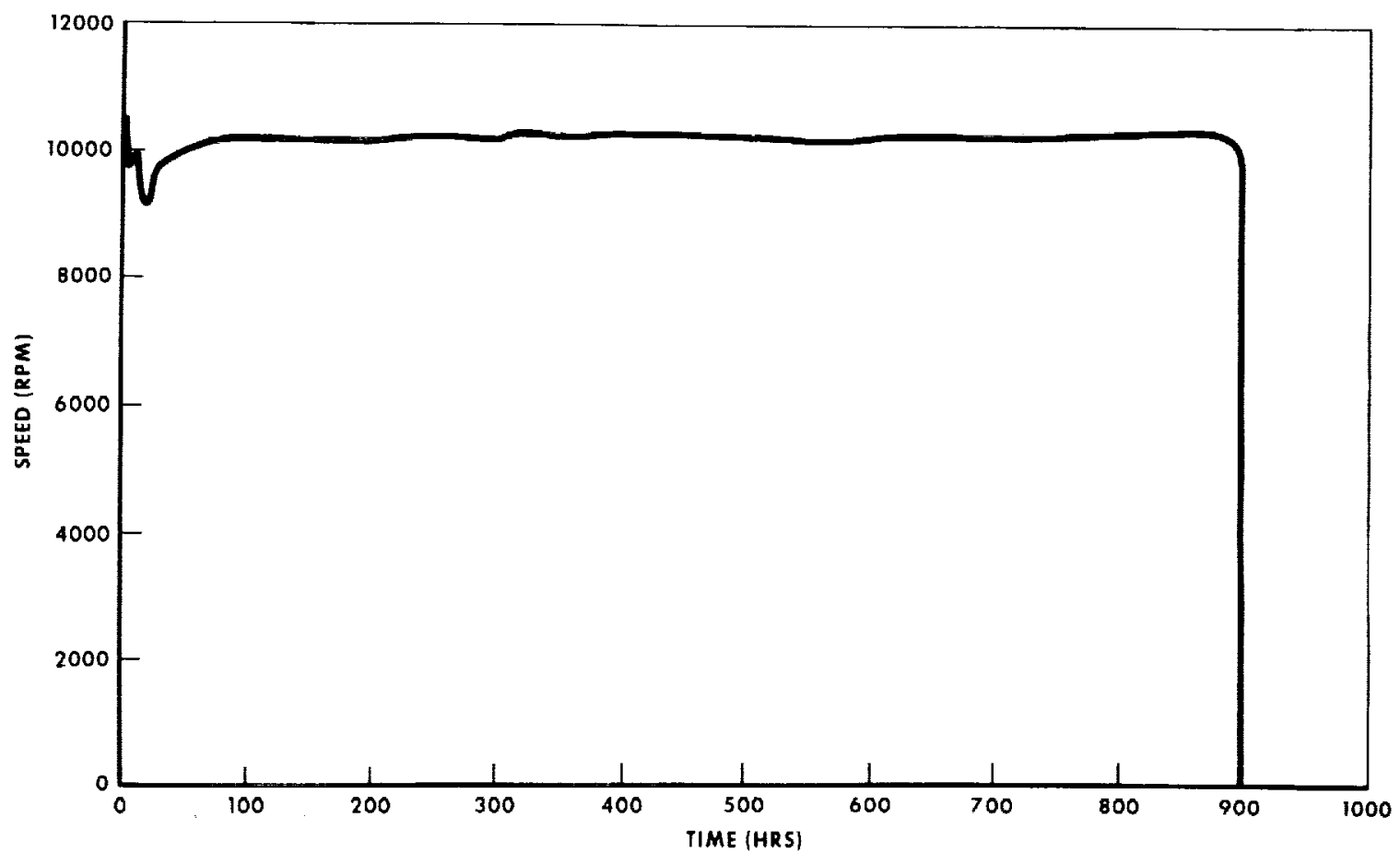

Figure 12 - Bearing test 14: R2-5 bearings, gold plated balls and races, and S-Inconel retainer

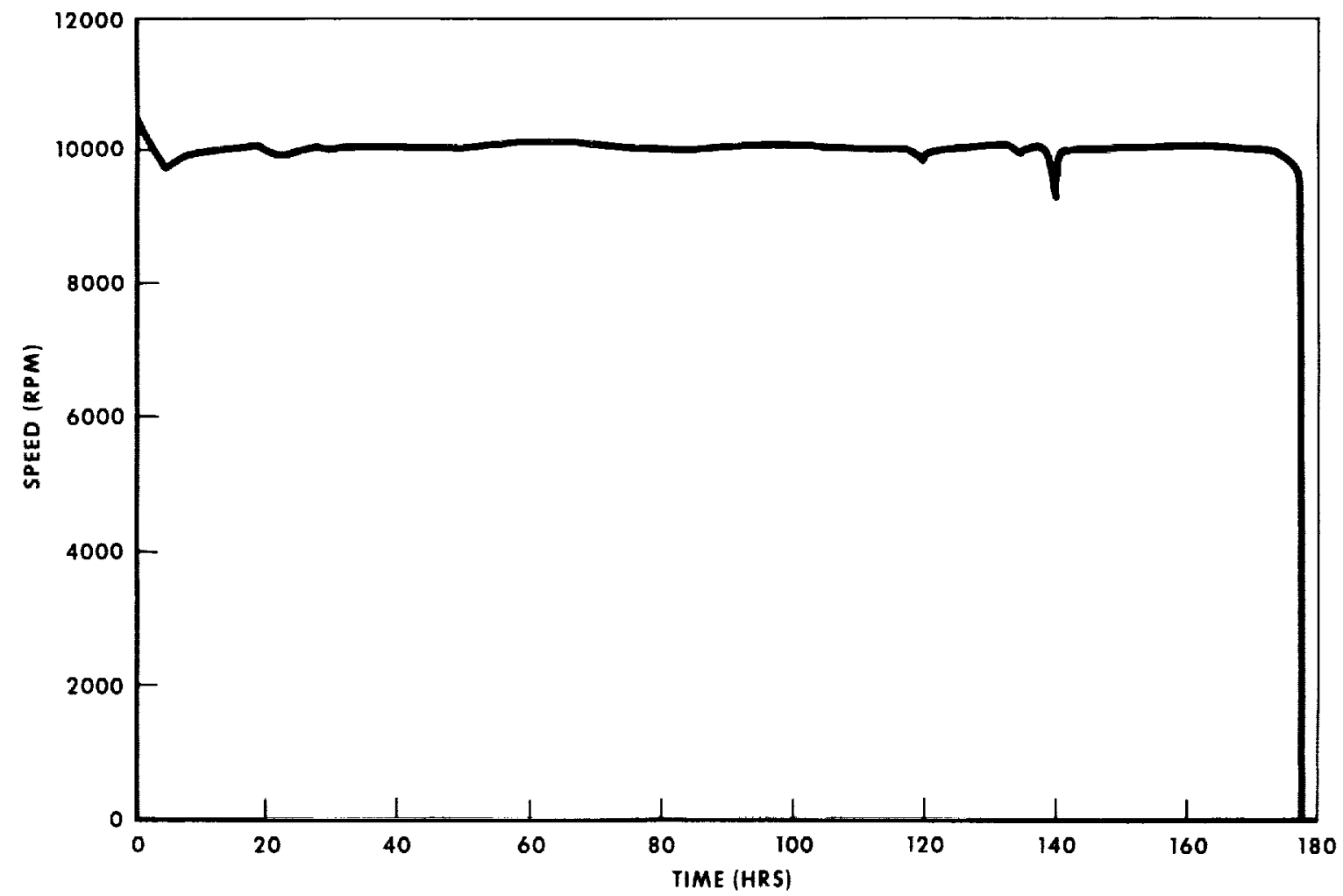

Figure 13 - Bearing test 16: R2-5 bearings, gold plated balls and races, and S-Inconel retainer 


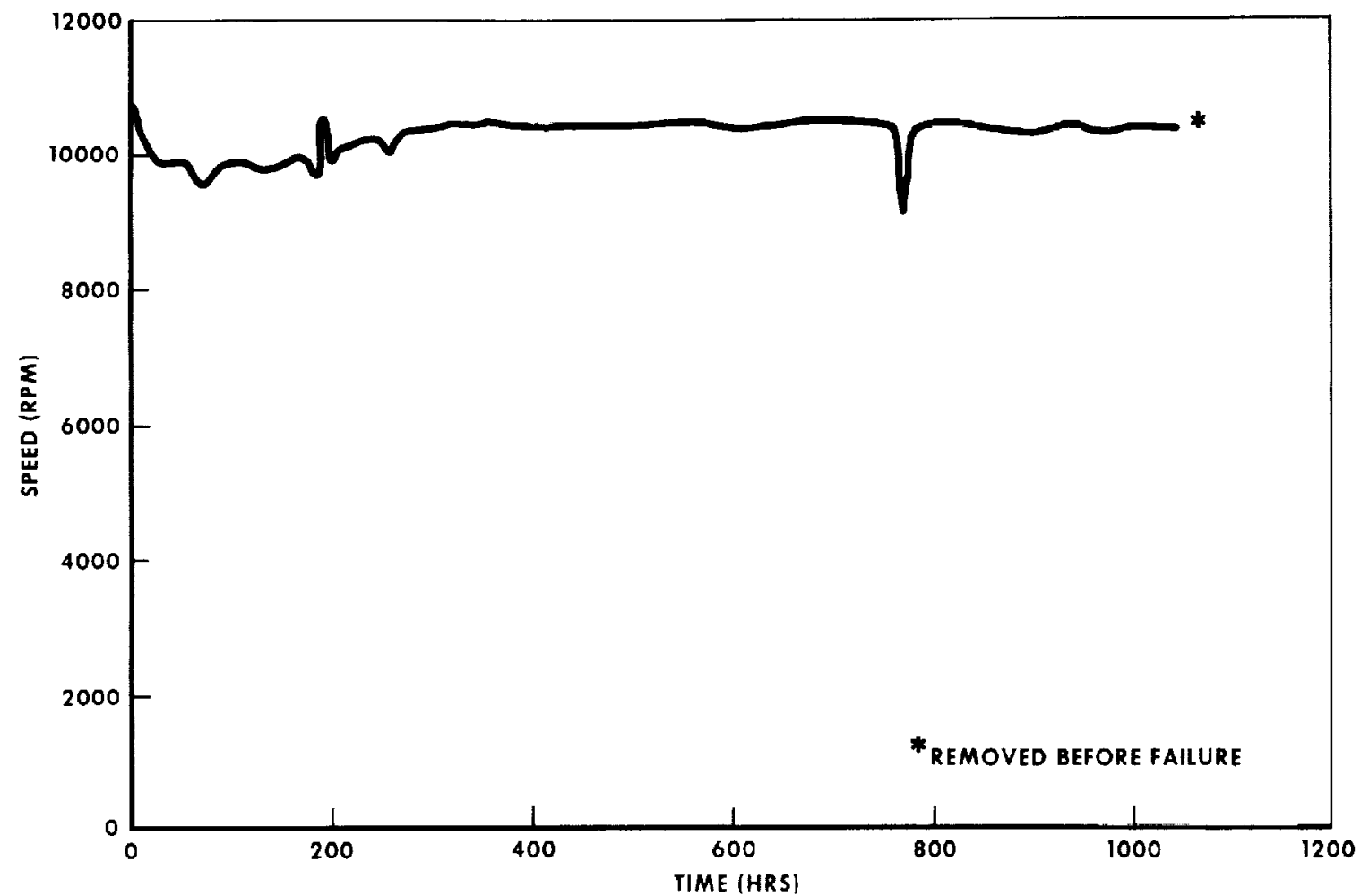

Figure 14 - Bearing test 18: R2-5 bearings, gold plated balls and races, silver plated circle $C$ retainer

\section{CONCLUDING REMARKS}

Thin metallic films show considerable promise when used as lubricants in a vacuum environment. When gold films are employed, a pure gold plating is not as effective as gold with additives. Fully machined retainers provide good performance and the use of relatively hard retainer materials significantly extends the useful lives of the bearings. The initial decrease in motor speed indicates that this type of bearing requires a "run-in" period, perhaps to compress the gold and improve the surface conditions. The failures experienced tend to be catastrophic, making the prediction of the onset of failure difficult.

Since retainers made from S-Inconel and silver plated Circle $\mathrm{C}$ both appear promising and the sample sizes tested do not permit a statistical analysis to establish the superiority of either, Phase II will be undertaken with both retainer materials. In addition, the value of the silver plating and the effect of hardening the Circle $\mathrm{C}$ material will be investigated further. 



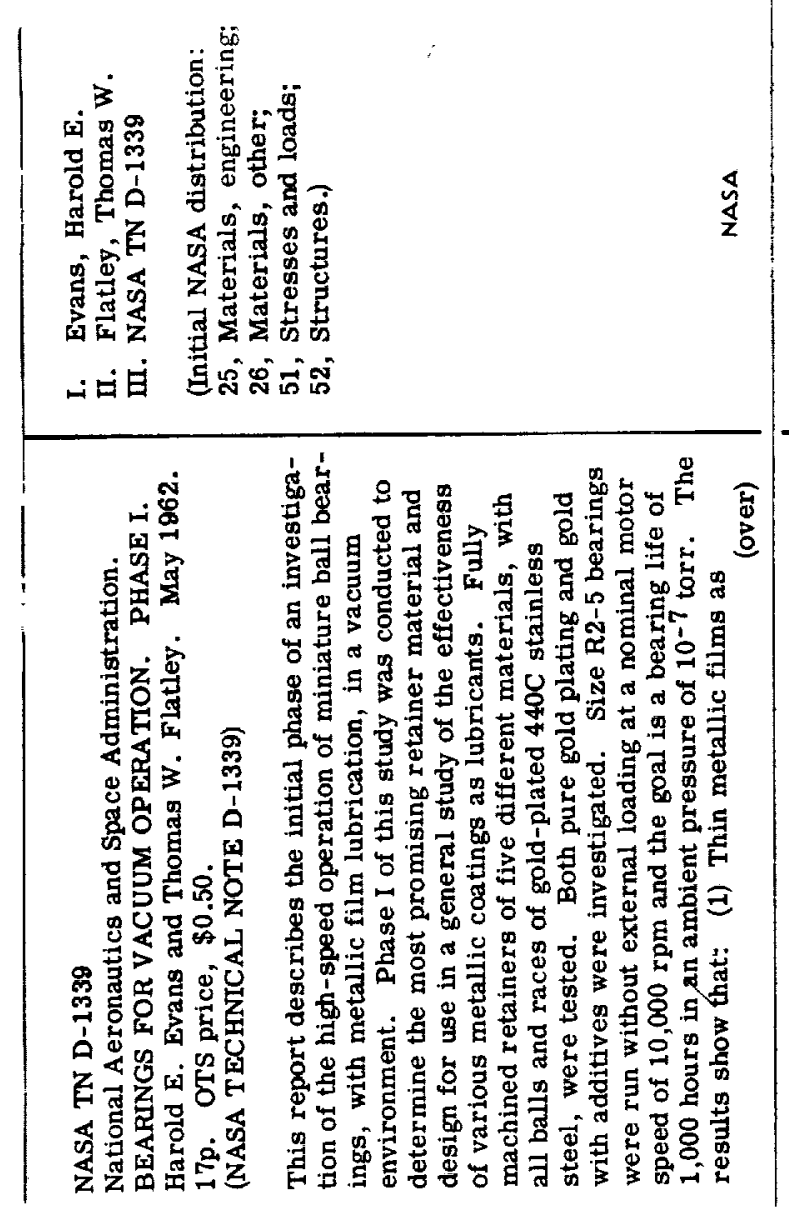

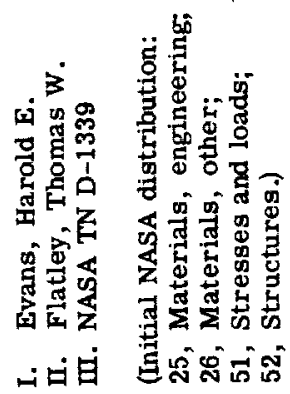

(1)
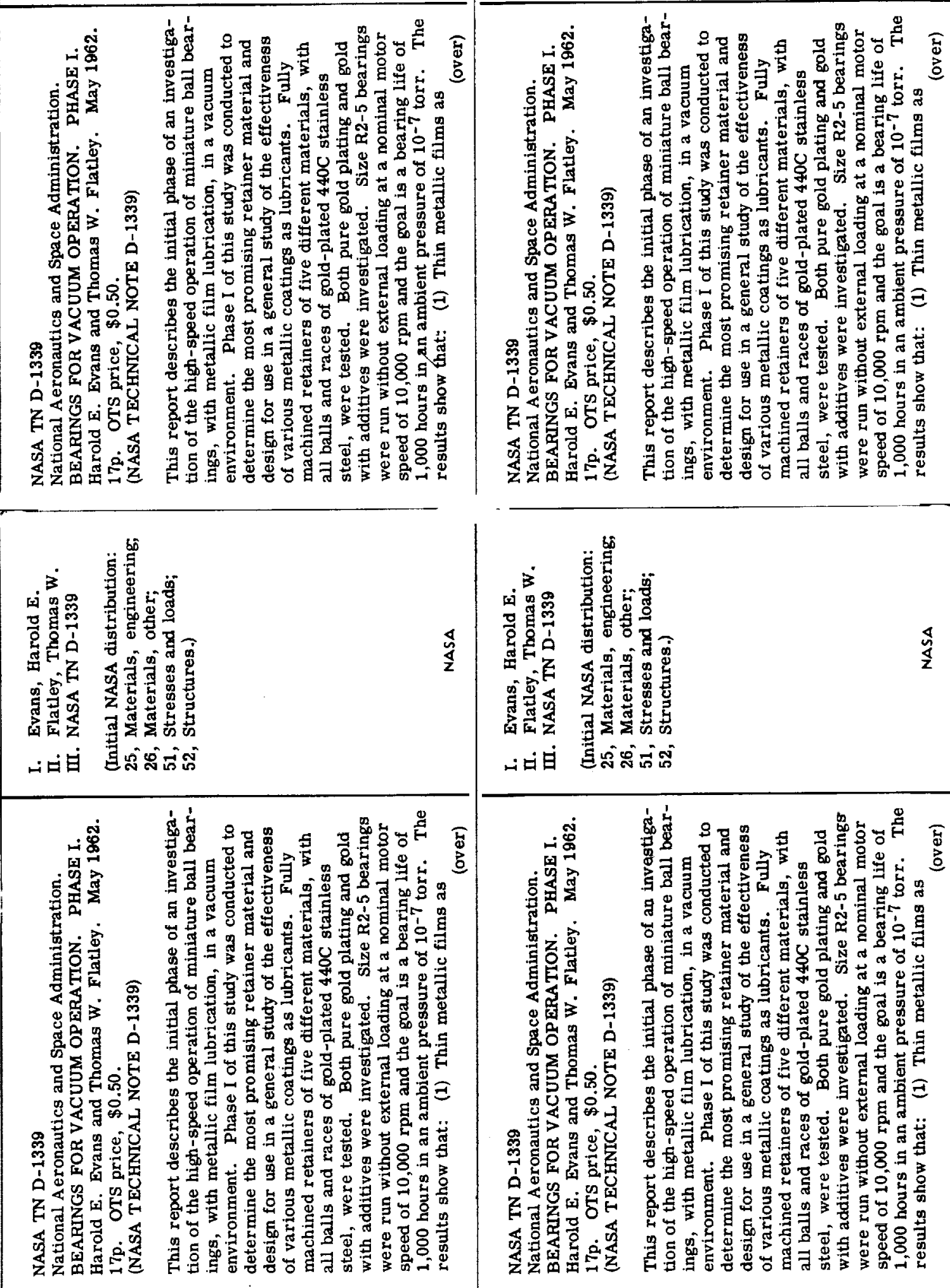

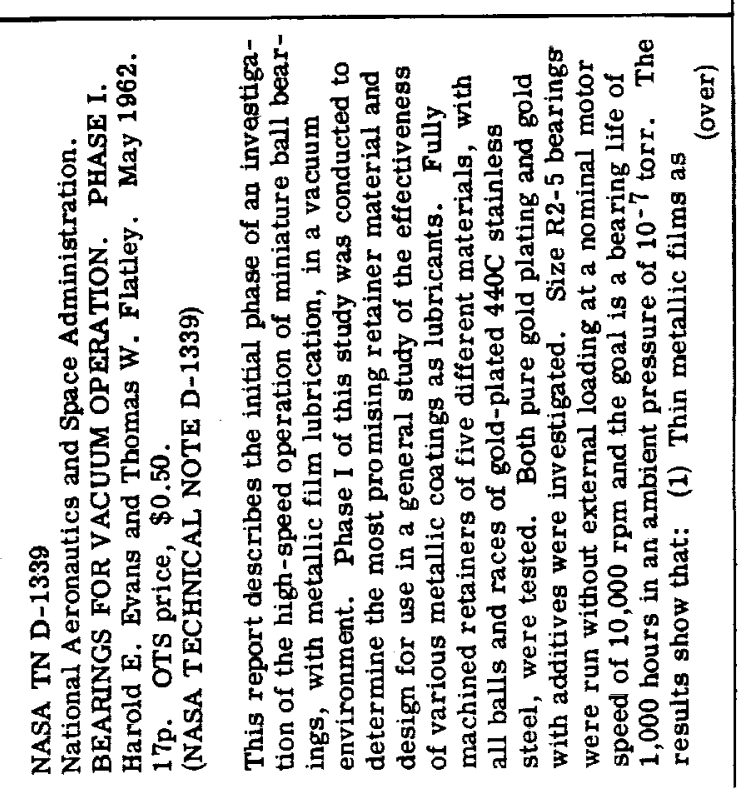



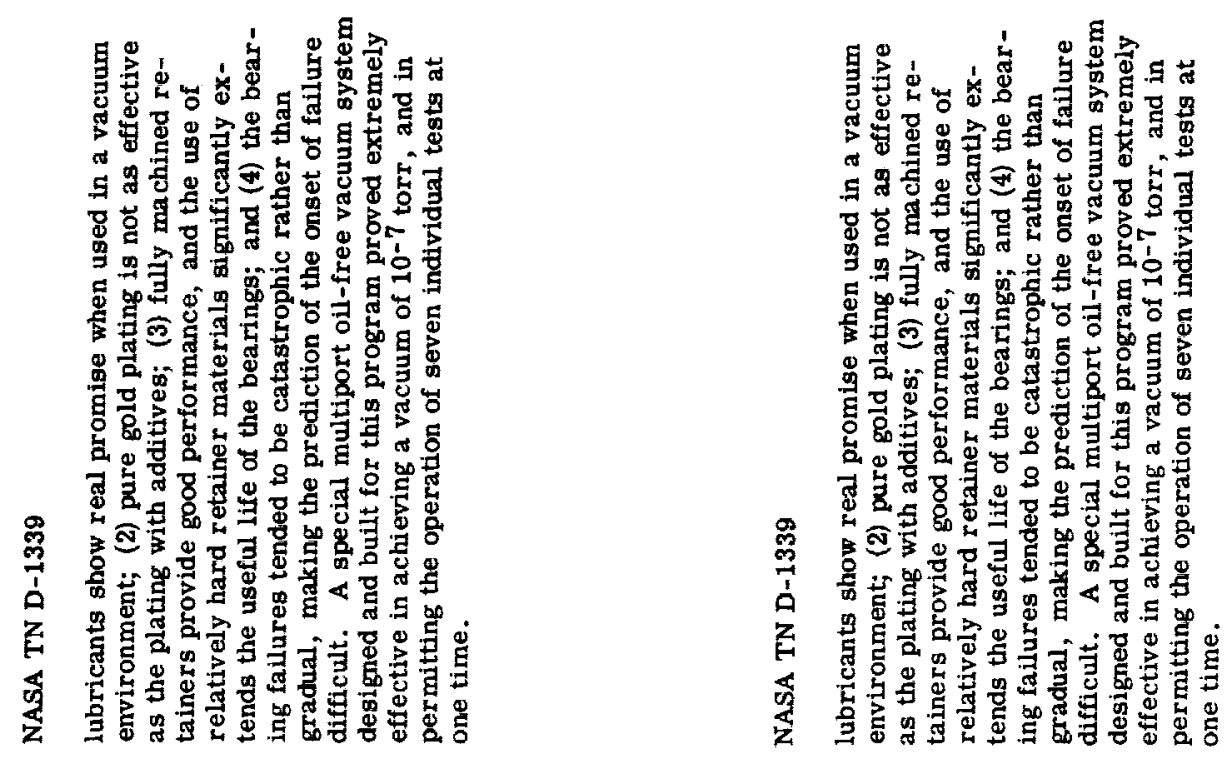

章
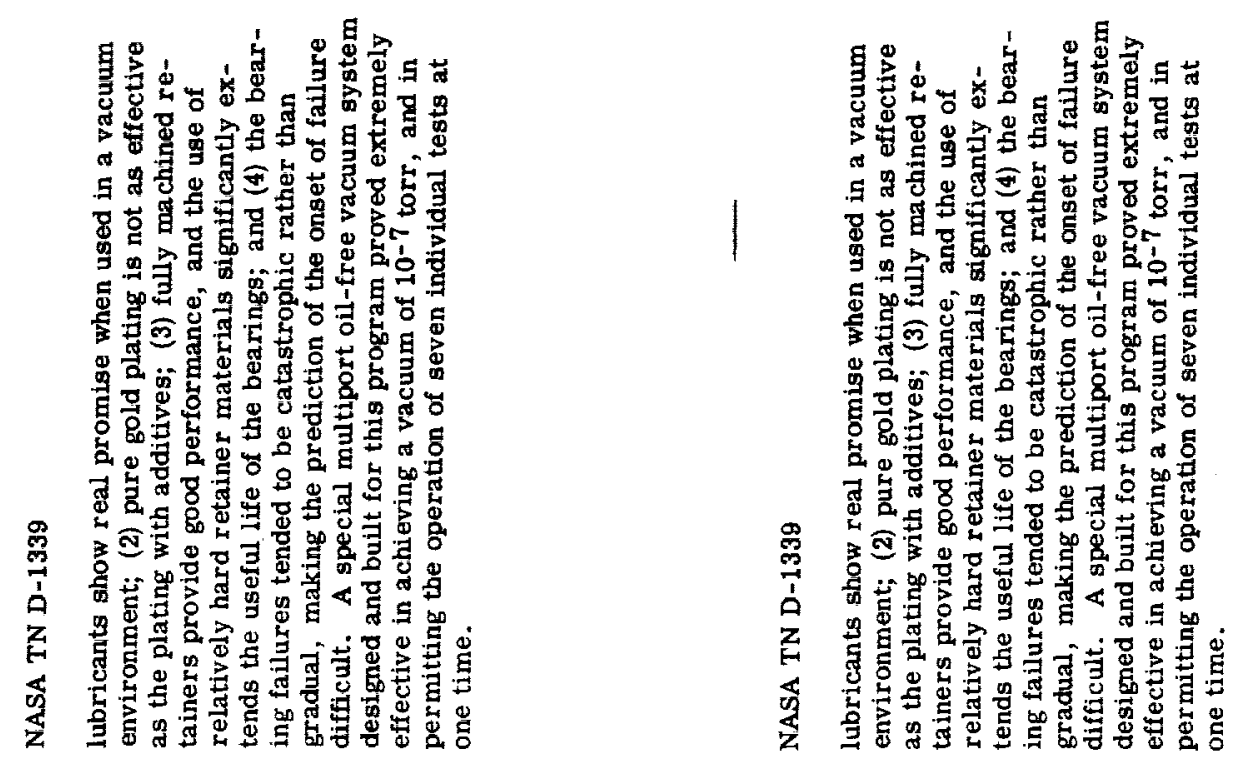